\title{
Adaptive E-Leering With Intelligent Decision For Group Suggestion
}

\author{
Mazin Haithem Razuly \\ Baghdad college of Economic Sciences university, Baghdad, Iraq.
}

Article History: Received:11 January 2021; Accepted: 27 February 2021; Published online: 5 April 2021

\begin{abstract}
Aabstract : many person used e-environment facility to developing human ability depend on ( hobbies , study field,..... etcetera) improving by e-learning now many person using this machine without classified user , any discussion between two or more than may be give new creative idea if those persons with same field with this paper attempt to design optimizing system to grouped user with same hobbies and interests for development human been by implementation candidate system with simulated e-environment achieved good result.
\end{abstract}

\begin{abstract}
Keywords: e-environment, e-learning, cloud computing and intelligent system
1-introduction

At the end of the last century, a great development occurred in the field of information technology and added great facilities for users of the electronic environment. Among these facilities is study and electronic education ..... To the last, the research paper in the next section will present concepts, definitions and methods available in e-learning and section $3 \mathrm{We}$ will present the proposed model. As for section 4 , we will explain the results obtained from the implementation of the proposed system, and the fifth and last section indicates the conclusions.
\end{abstract}

2-e-learing definition, tools and adaptive e-learning

Attempt with this section, to give some important concepts and techniques that may be used in elearning and interactive e-learning, and some techniques used to implement these applications.

\section{1 e-learning main tools}

A Course Management System (CMS) is an electronic framework with a database back-end. A CMS helps instructors in acquiring assets on the web for understudies and to encourage the administration obviously exercises and assignments [1]. Some of regular e-learning frameworks accessible are WebBoard, WebCT, and Blackboard; from the open source there are: MOODLE, and Sakai [2]. An investigation directed by the University of Queensland (UQ) [3] exhibits that one of the most widely recognized effective technique in encouraging enormous classes is the utilization of electronic course material (e.g., course site, online assets, conversation sheets and so forth.) and utilization of blended media in addresses (e.g., power point, overhead, and so forth.). These days, utilization of online course the board frameworks is broad in instruction [4]. There are three qualities of online course the board frameworks are: availability obviously assets to understudies, opportune correspondence among teachers and learners and lessen paper utilization (paperless frameworks). A CMS is not the same as an up close and personal course. Up close and personal course is a customary learning, utilized in study hall and it doesn't require a Web situation. Though, the web-upgraded course is a cross breed (conventional and on the web) and it can nearly be utilized in neighborhood condition. Then again, electronic course is constantly on the web, can be utilized in separation learning and all the activities in online course require a Web association [4][5]. A web course has number of favorable circumstances including [4]:

- It is an advantageous and comprehensive at whenever

- It is dynamic and paperless learning

- It assists with building abilities and creative

- It is open to learning

- Web course makes the instructing is simpler One of the fundamental qualities of CMS is a security and protection.

Security and protection methods have been executed in the CMS to do the accompanying errands [5]:

- Student get to controlled to exercises and undertakings 
- Guest get to controlled to exercises and errands

- Lecturer's Intellectual Property (IP) shielded

- Copyrighted materials made sure about from programmers and wafers

- Student security shielded from crooks

- Course content specifically discharged and refreshed

- Assignment entries logged

- Tests and assignments progressively secure utilizing a few degrees of security MOODLE, and Blackboard are three normal online learning the executives frameworks broadly utilized in instruction, preparing, and information the board. This paper analyzes them practically, with a specific spotlight on the utilizing in the educating and learning of courses [4].

\subsection{Crawling meaning}

The strategy for the mass downloading of site pages called web crawler (too distinguished as a creepy crawly or a robot). It is utilized for some capacities. Most critically, web crawlers are one of the significant segments of web search frameworks, frameworks that gather a measure of site pages, record them, and permit clients to discover the site pages that coordinate the questions subsequent to giving inquiries against the record. Web documenting is a related utilization (a help provided by e.g., the Web document [5][6][7][8])

\section{3 intelligent system}

Any intelligent tools such as genetic ,neural .. etcetera with observer system to improve adaptivity for any system [8][ 9]

3. candidate system

With this section clear main engine that used to improve system function as :

Algorithm 1

1 start

2 fetch employs profile to detected experiences, hobbies ...etcetera

3 call classifier procedure // 2,3 to built grouped

4 call developer system //t o suggested grouped

5 call problem selective // to solve main organization problem

6 end

Algorithm 2

// fetch employs profile and group creator

1 start

2 while not end of employs list do

-Read experience, hobbies

-current job efficient

-recorded with employs ID

3 for $\mathrm{i}=1$ to no. of hubbies that detection

create group [i] depend on main hubbies available 


\section{4 end}

\section{Algorithm 3}

// description rule for organization internal chat system machine

// automatic download paper or software depend on main hobbies or //experience

//

1 start

2 internal chat system rule as

Only using employ ID

If any ID say Name or job position then

Automatic block and denoted as unstable employ

End if

3 go to 2

Algorithm 4

// suggestion group and denoted which not available must put in nearest

// group or (reject from job after questioner )

1 start

2 call chat observation

$3 n=1$

4 while (chat_value[n]) and ( $<==$ employ_no) do

For i=0 to group_no_depend_classify

If $s \_g r u o p[i]=h o b b i e s$ or experience or job then

Put ID[n] , S_group[i], as group suggestion

Else

Denoted ID[n] as mutation ID[n]

End if

Next i

n++

5 end

Algorithm 5

// check employs grouped acceptation to start developing 
1 start

2 for I 1 to employs no.

If any rejection occurrence then

send questioner why not improve

else

send congratulation for group acceptation and what need to development experiences

end if

3 start with employs requirement (paper, software ...etcetera)

4 while online start with download available requirement may be need when off line system to developing or solving problem

5 check using of requirement if not use block and refused from group

6 end

Algorithm 6

// spreading sample problem to all group and gathering solution which

//group is best

1 start

2 for $\mathrm{i}=$ to group no.

Spreading question for group[i] // as specific depend on group type

Next i

3 for $\mathrm{i}=1$ to group no

Gathering answer and auto checking

4 end

4- experimental result

With this section show the main result that achieve from implementation of simulation system see table 1

Table 1: data from HR system developer and observer

\begin{tabular}{|l|l|l|l|l|l|l|l|l|}
\hline company & employ & hubbies & group & $\begin{array}{l}\text { group } \\
\text { response }\end{array}$ & $\begin{array}{l}\text { Not } \\
\text { response }\end{array}$ & require & benefit & unused \\
\hline 1 & 63 & 1 & 1 & 18 & 45 & 5 & 1 & 4 \\
\hline 2 & 62 & 4 & 3 & 36 & 26 & 15 & 11 & 4 \\
\hline 3 & 204 & 1 & 1 & 108 & 96 & 5 & 5 & 0 \\
\hline 4 & 83 & 4 & 4 & 49 & 34 & 22 & 6 & 16 \\
\hline 5 & 189 & 5 & 5 & 65 & 124 & 29 & 2 & 27 \\
\hline 6 & 298 & 1 & 1 & 126 & 172 & 5 & 2 & 3 \\
\hline 7 & 15 & 3 & 1 & 11 & 4 & 5 & 3 & 2 \\
\hline
\end{tabular}


Mazin Haithem Razuly

\begin{tabular}{|c|c|c|c|c|c|c|c|c|}
\hline 8 & 262 & 2 & 1 & 211 & 51 & 5 & 1 & 4 \\
\hline 9 & 46 & 1 & 1 & 42 & 4 & 5 & 2 & 3 \\
\hline 10 & 173 & 8 & 6 & 7 & 166 & 30 & 14 & 16 \\
\hline 11 & 1 & 5 & 4 & 1 & 0 & 21 & 19 & 2 \\
\hline 12 & 8 & 8 & 3 & 4 & 4 & 16 & 16 & 0 \\
\hline 13 & 89 & 6 & 2 & 1 & 88 & 11 & 4 & 7 \\
\hline 14 & 326 & 5 & 1 & 147 & 179 & 5 & 2 & 3 \\
\hline 15 & 265 & 3 & 2 & 96 & 169 & 11 & 8 & 3 \\
\hline 16 & 126 & 8 & 3 & 13 & 113 & 15 & 11 & 4 \\
\hline 17 & 203 & 9 & 3 & 8 & 195 & 15 & 15 & 0 \\
\hline 18 & 201 & 2 & 1 & 162 & 39 & 5 & 5 & 0 \\
\hline 19 & 158 & 3 & 3 & 5 & 153 & 15 & 3 & 12 \\
\hline 20 & 37 & 6 & 5 & 31 & 6 & 27 & 13 & 14 \\
\hline 21 & 224 & 10 & 1 & 16 & 208 & 5 & 4 & 1 \\
\hline 22 & 240 & 6 & 2 & 213 & 27 & 11 & 10 & 1 \\
\hline 23 & 143 & 5 & 4 & 100 & 43 & 21 & 13 & 8 \\
\hline 24 & 40 & 2 & 2 & 33 & 7 & 10 & 9 & 1 \\
\hline 25 & 338 & 6 & 1 & 126 & 212 & 5 & 5 & 0 \\
\hline 26 & 208 & 5 & 5 & 105 & 103 & 29 & 13 & 16 \\
\hline 27 & 293 & 10 & 9 & 29 & 264 & 48 & 23 & 25 \\
\hline 28 & 300 & 9 & 1 & 157 & 143 & 5 & 3 & 2 \\
\hline 29 & 9 & 7 & 6 & 2 & 7 & 31 & 30 & 1 \\
\hline 30 & 11 & 10 & 10 & 11 & 0 & 50 & 19 & 31 \\
\hline 31 & 300 & 10 & 4 & 249 & 51 & 23 & 7 & 16 \\
\hline 32 & 325 & 10 & 9 & 98 & 227 & 52 & 37 & 15 \\
\hline 33 & 144 & 1 & 1 & 35 & 109 & 5 & 5 & 0 \\
\hline 34 & 50 & 4 & 1 & 1 & 49 & 5 & 2 & 3 \\
\hline 35 & 99 & 5 & 4 & 23 & 76 & 22 & 13 & 9 \\
\hline 36 & 235 & 1 & 1 & 5 & 230 & 5 & 5 & 0 \\
\hline 37 & 90 & 2 & 2 & 30 & 60 & 11 & 4 & 7 \\
\hline 38 & 199 & 8 & 1 & 28 & 171 & 5 & 3 & 2 \\
\hline 39 & 267 & 3 & 3 & 112 & 155 & 17 & 12 & 5 \\
\hline 40 & 163 & 9 & 9 & 129 & 34 & 48 & 42 & 6 \\
\hline 41 & 111 & 3 & 2 & 11 & 100 & 11 & 4 & 7 \\
\hline 42 & 238 & 2 & 2 & 54 & 184 & 10 & 6 & 4 \\
\hline 43 & 66 & 7 & 2 & 54 & 12 & 11 & 11 & 0 \\
\hline 44 & 74 & 7 & 3 & 18 & 56 & 16 & 1 & 15 \\
\hline 45 & 225 & 7 & 3 & 29 & 196 & 16 & 1 & 15 \\
\hline 46 & 113 & 6 & 2 & 65 & 48 & 10 & 1 & 9 \\
\hline 47 & 309 & 7 & 5 & 150 & 159 & 29 & 12 & 17 \\
\hline 48 & 77 & 7 & 1 & 18 & 59 & 5 & 2 & 3 \\
\hline 49 & 153 & 8 & 2 & 25 & 128 & 10 & 7 & 3 \\
\hline 50 & 152 & 10 & 3 & 101 & 51 & 15 & 1 & 14 \\
\hline
\end{tabular}

Figure 1 :Relation between number or employs and hubbies 


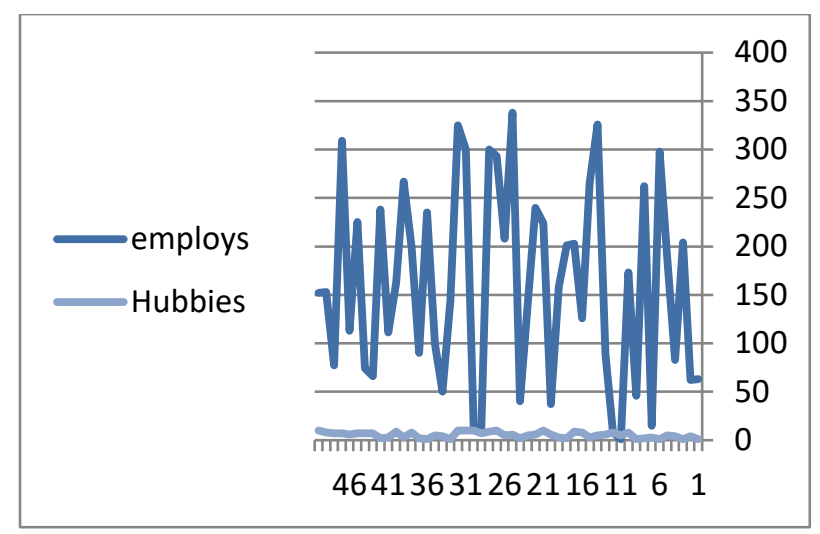

Figure 1:number of employs and hubbies

Figure 2 is relation between number of problems and number of solving

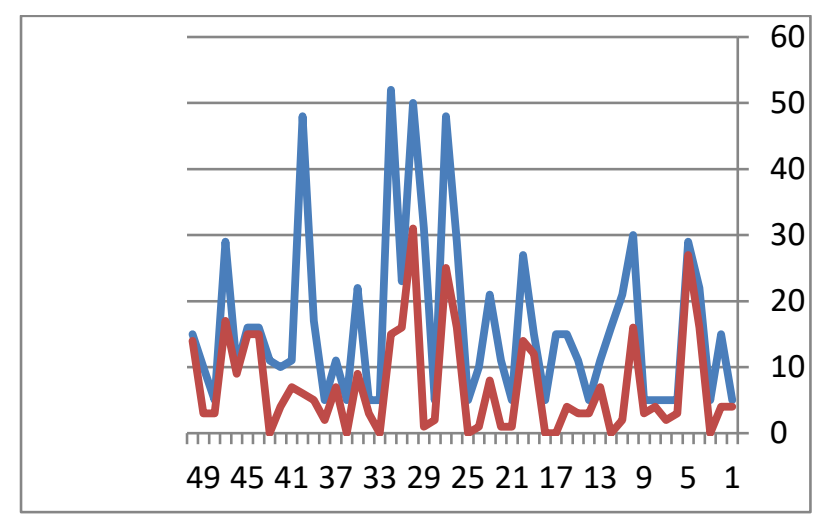

Figure 2:requirement and number of unused

When operate chat system observing with auto reject for any one need to know whom chat with you have the following table, table 2 clear that. And chart 3 represent data of table 2.

Table 2 :employs and chat observer

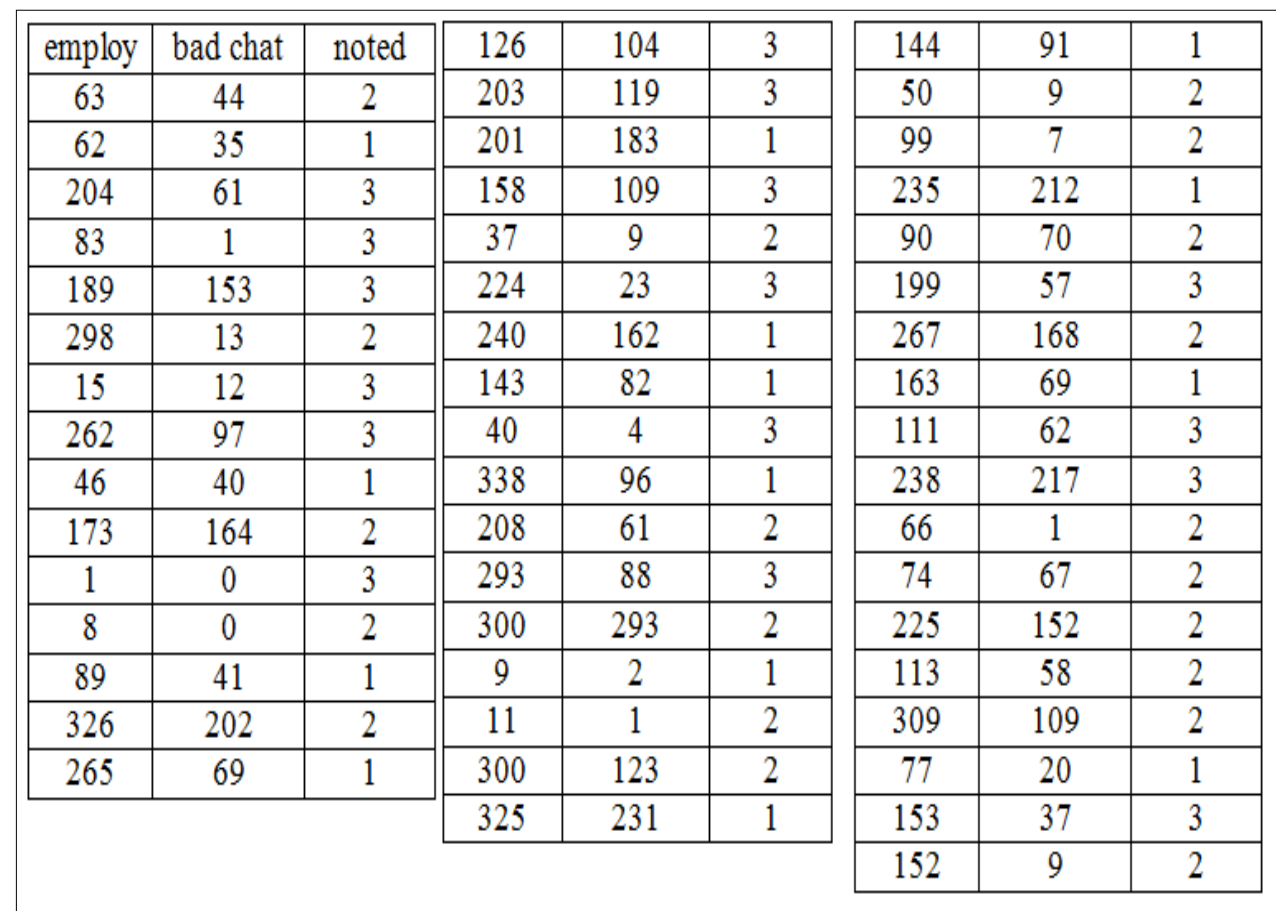




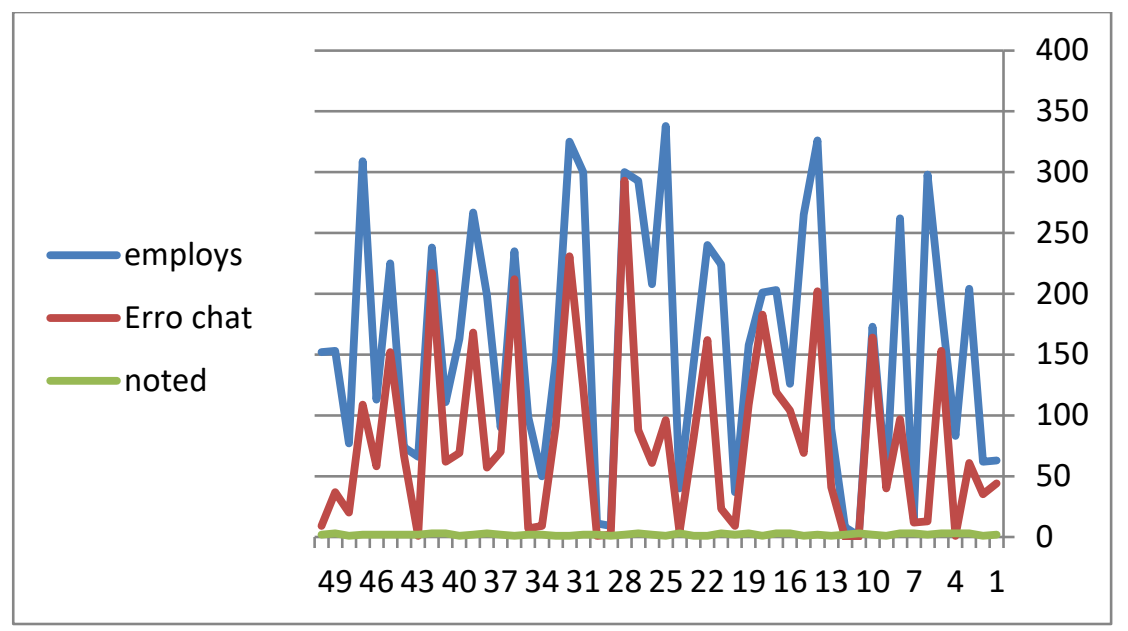

Figure 3:employs and chat system

\section{5- conclusion}

In this section clear concluded point from implementation

1- Many hubbies for employs may give good functionality for organization .

2- Number of employs with limited ability as not available need requirement but not used to upgreat experiences .

3- Must observing chat system with unknown person only used ID improve real optimizing with team job at the same group.

4- System when work on-line and off-line to support employs requirement increase ability

\section{References}

1. V. Tan, "Using IVLE to Teach Large Classes - A Personal Experience", TLHE 2004 Proceedings, p. 443-448.

2. E.M. Knorr, "Course Management System (CMS) Evaluation and Strategy at UBC: A Viewpoint from the

Faculty of Science", Department of Computer Science, University of British Columbia, 2008.

3. Teaching and Educational Development Institute, University of Queensland, "Teaching Large Classes Project 2001", Report 2003.

4. L. MacPhee, E. Shelley, G. Karcz, How can a course management system (CMS) enhance my online (or faceto face) course? Center for Technology Enhanced Learning,2009.

5. Gupta, Satinder Bal, "The Issues and Challenges with the Web.", International Journal of Information Technology \& Systems(ISSN: 2277-9825), Vol. 1 No. 1, 2012, pp.1-10.

6. Richard W.Riley. "E-Learning Putting a World-Class Education at the Fingertips of All Children (The National Educational Technology Plan), U.S. Department of Education, Office of Education, Office of Educational Technology,2015 pp. 1-74

7. T.M. Duffy and R. j. Kirkly," Learner-Centered Theory And Practice In Distance Education”, Lawrence Erlbaum Associates, 2004.

8. W. Horton and K. Horton," E-learning Tools and Technologies", Wiley Publishing Inc, 2003.

9. Dybkowski " Stator-Current-Based MRAS Estimator for a Wide Range Speed-Sensorless IM drive Teresa orlowska-kowalska, Senior Member, IEEE, Mateusz IEEE Transactions on industrial electronics, 2010 . 